Article

\title{
One-pot synthesis of a hierarchical microporous-mesoporous phosphotungstic acid-HKUST-1 catalyst and its application in the selective oxidation of cyclopentene to glutaraldehyde
}

\author{
Xinli Yang a,\#, Liming Qiao a, Weilin Dai b,* \\ a School of Chemistry \& Chemical Engineering, Henan University of Technology, Zhengzhou 450001, Henan, China \\ ${ }^{\mathrm{b}}$ Department of Chemistry and Shanghai Key Laboratory of Molecular Catalysis and Innovative Materials, Fudan University, Shanghai 200433, China
}

A R T I C L E I N F O

Article history:

Received 15 July 2015

Accepted 10 September 2015

Published 20 November 2015

Keywords:

Metal-organic frameworks

HKUST-1

Phosphotungstic acids

Cyclopentene

Glutaraldehyde

\begin{abstract}
A B S T R A C T
A hierarchical microporous-mesoporous metal-organic framework of HKUST-1(Cu)-encapsulated phosphotungstic acid (HPW) material, referred to as HPWs@Meso-HKUST-1, is prepared by a one-pot synthesis method using cetyltrimethylammonium bromide as the supramolecular template. The addition of HPWs to the synthesis mixture of hierarchical porous HKUST-1 results in the direct encapsulation of HPWs inside the mesopores of the HKUST-1 structure, with a homogeneous distribution over the HKUST-1 crystals, which is confirmed by XRD, FT-IR, $\mathrm{N}_{2}$ adsorption, UV-Vis DRS, and TEM. FT-IR-CO adsorption experiments indicated that additional Lewis acid sites were present in the HPWs@Meso-HKUST-1 sample. The novel heterogeneous catalyst demonstrates excellent catalytic performance for the selective oxidation of cyclopentene (CPE) to glutaraldehyde (GA) using tert-butyl hydroperoxide and acetonitrile $(\mathrm{MeCN})$ as the oxidant and solvent, respectively. The high activity of the catalyst is attributed to the mesostructure of the catalyst and the nature and appropriate abundance of the HPWs-being highly dispersed with the addition of Lewis sites. After a reaction for $36 \mathrm{~h}$, the 30\% wt\% HPWs@Meso-HKUST-1 catalyst exhibits a CPE conversion of 92.5\% and a high GA yield of 73\%. Furthermore, the HPWs@Meso-HKUST-1 material is sufficiently stable to prevent the leaching of HPWs, and behaves as a true heterogeneous catalyst that can be repeatedly recycled without sustaining a loss of activity and selectivity in the selective oxidation of CPE.
\end{abstract}

(C) 2015, Dalian Institute of Chemical Physics, Chinese Academy of Sciences. Published by Elsevier B.V. All rights reserved.

\section{Introduction}

Heteropolyacids (HPAs), as a unique class of anionic metal-oxygen clusters of early transition metals, possess many properties that make them candidates for application in cataly- sis. HPAs have been extensively used as acid and oxidation catalysts in many reactions since their acid-base and redox properties can be tuned easily by changing the polyanion chemical composition [1]. Phosphotungstic acid (HPW) with the strongest Brönsted acidity in the HPAs series has promise

\footnotetext{
* Corresponding author. Tel: +86-21-55664678; Fax: +86-21-55665701; E-mail: wldai@fudan.edu.cn

\# Corresponding author. Tel: +86-371-67756718; Fax: +86-371-67756718; E-mail: xlyang@haut.edu.cn

This work was supported by the Plan of Nature Science Fundamental Research in Henan University of Technology (2013JCYJ09), the Fundamental Research Funds for the Henan Provincial Colleges and Universities (2014YWQQ13), and the National Natural Science Foundation of China (20903035, 21373054).

DOI: 10.1016/S1872-2067(15)60972-X | http://www.sciencedirect.com/science/journal/18722067 | Chin. J. Catal., Vol. 36, No. 11, November 2015
} 
as a heterogenous catalyst for many organic reactions, such as esterification, alkylation, hydrolysis, and oxidation [1,2]. However, the pure bulk HPAs present relatively small surface areas $\left(<10 \mathrm{~m}^{2} / \mathrm{g}\right)$ that hinder accessibility to the active sites. Therefore, the applications of HPAs as solid catalysts are limited. Thus, various high-surface-area supports, such as silica $[3,4]$, activated carbon [5,6], ion-exchange resin [7], and mesoporous molecular sieves [8-10], have been used for HPA dispersion. Additionally, the supported HPA catalysts usually display low activities because of low HPA loading, HPA leaching, the conglomeration and non-uniformity of HPA particles and the deactivation of acid sites by water. Therefore, the immobilization of HPAs in a suitable solid matrix, which can overcome these drawbacks, is a step toward the challenging goal of catalysis. Metal-organic frameworks (MOFs), the newest generation of porous materials, can be used as host matrices to encapsulate HPAs and form a series of unique, tunable catalysts.

MOFs are hybrid inorganic-organic crystalline solids formed by the linkage of single metal ions or metal clusters with tunable oligotrophic organic ligands. Over the last few decades, MOFs have attracted considerable attention because of their unique ensemble of properties, such as high surface area, crystalline open structure, tunable pore size, and functionality. These materials have demonstrated immense potential in application of luminescence, magnetism, separation, gas storage, drug delivery, and heterogeneous catalysis [11-13]. The copper-based MOF, HKUST-1 (Cu-BTC or MOF-199), with a structural formula of $\mathrm{Cu}_{3}(\mathrm{BTC})_{2}$ (BTC $=1,3,5$-benzenetricarboxylate), is one of the most intensively investigated and characterized structures in the field of MOFs [14]. This material was first reported by Chui et al. [15] in 1999, and its crystalline structure consists of a so-called copper paddle wheel, with a $\mathrm{Cu}-\mathrm{Cu}$ distance of $0.263 \mathrm{~nm}$, where each copper atom is octahedrally coordinated by four oxygen atoms of the BTC linkers and by one water molecule (solvent). The water molecules can be easily removed by heating under vacuum, which leaves unsaturated $\mathrm{Cu}$ sites available for adsorption and catalytic transformation (material activation). Additionally, benzene rings are bonded to three dimeric cupric tetracarboxylate units. MOF-based catalysts have to exhibit sufficient stability under the applied reaction conditions, including thermal stability and chemical resistance, in addition to the presence of accessible active catalytic sites. Cu-BTC exhibits all prerequisite properties; hence, the material has been used as the active catalyst itself in the cyanosilylation of carbonyl compounds [16], the isomerization of $\alpha$-pinene oxide, the cyclization of citronellal [17], and oxidation or epoxidation [18-21]. As a well-known MOF, Cu-BTC has also been used as a stable host to encapsulate various Keggin-type HPAs, whose attractive catalytic performance can be endowed by the HPAs@Cu-BTC [22-26].

However, hitherto, most of the MOFs reported are still restricted to the microporous regime, which hinders fast molecular diffusion and mass transfer. In addition, micropores are seldom accessible for anchoring molecular catalysts or impregnating catalyst precursors or voluminous drug molecules, thereby limiting their applications in fine chemical transformation, nanoparticle formation, or drug delivery [27]. Thus, considerable efforts have been made to expand the pore widths of MOFs to the mesoporous regime, including the use of elongated organic ligands, post-synthetic modification, a combination of mixed ligands, the use of surfactants as structure-directing agents, and using specially designed spacers with hierarchical functional groups, among others. Recently, Fang et al. [28], Xuan et al. [29], and Sun et al. [30] have independently reported important reviews on mesoporous MOFs. The presence of mesopores in MOFs markedly expands their use as hosts to accommodate large bulky molecules, allowing their reaction or transformation without the limitations of diffusion in a confined space. However, in practice, the heat of adsorption is somewhat reduced. Despite this reduction, large-pore MOFs generally outperform small-pore MOFs; hence, their synthesis and characterization are thoroughly investigated and targeted for a wide range of applications.

Qiu et al. [31] have successfully applied a surfactant-templated route for synthesizing hierarchically micro- and mesoporous HKUST-1 with tailored porosities. Phosphotungstic acid (HPW) has been proven to be an efficiently homogeneous catalyst for the selective oxidation of cyclopentene (CPE) to glutaraldehyde (GA) [32], which is extensively used for disinfection and sterilization. The selective oxidation of CPE is an important method for producing GA, as significant quantities of CPE can be easily obtained by the selective hydrogenation of cyclopentadiene, which is easily obtained from the decomposition of dicyclopentadiene; dicyclopentadiene is the main by-product from the $\mathrm{C}-5$ fraction in the petrochemical or coking industry $[33,34]$. The work herein investigates if the catalytic activity of the HPW catalyst is enhanced when encapsulated in the hierarchically porous HKUST-1 support, compared with HPW alone in the selective oxidation of CPE to GA.

Herein, the novel HPWs@Meso-HKUST-1 catalyst was synthesized by a one-pot synthesis method using $\mathrm{Cu}^{2+}$ and BTC as the framework building block, cetyltrimethylammonium bromide (CTAB) as the structure-directing agent, and HPW as the active component. Analysis revealed that HPWs were uniformly encapsulated in the disordered nanoscale mesopores of HKUST-1, leading to an improvement in GA yield for the selective oxidation of CPE to GA.

\section{Experimental}

\subsection{Catalyst preparation}

HKUST-1 was synthesized according to the hydrothermal method described in Ref. [15].

The encapsulation of HPWs in microporous HKUST-1 followed the same procedure as described in Ref. [15,35] with respect to the synthesis mixture and cleaning. However, the HPWs were added in situ to the Teflon container with the rest of the mixture. The as-prepared material was denoted as HPWs@HKUST-1.

The encapsulation of HPWs in the hierarchical microporous-mesoporous HKUST-1(Cu) was synthesized by a one-pot synthesis method. In a typical synthesis, $0.70 \mathrm{~g}$ of $\mathrm{H}_{3} \mathrm{BTC}$ and $0.12 \mathrm{~g}$ of CTAB were dissolved in $16 \mathrm{~mL}$ of absolute 
ethanol. A separate solution containing $1.45 \mathrm{~g}$ of $\mathrm{Cu}\left(\mathrm{NO}_{3}\right)_{2} \cdot 3 \mathrm{H}_{2} \mathrm{O}$ dissolved in $12 \mathrm{~mL}$ of distilled water was prepared. Both solutions were combined and mixed under vigorous stirring for approximately $30 \mathrm{~min}$. Thereafter, the mixtures were transferred into a Teflon-lined autoclave and HPWs were added to the Teflon container. Finally, the obtained mixtures were isolated in the autoclave and subjected to crystallization temperatures at $393 \mathrm{~K}$ for $12 \mathrm{~h}$ in an oven under static conditions. After the desired time, the synthesis mixture was naturally cooled to room temperature. The solid product was filtered and washed with water and ethanol. To remove CTAB, a solvothermal treatment was performed using absolute ethanol under reflux at $351 \mathrm{~K}$ for $3 \mathrm{~h}$ and repeated three times. The as-prepared catalyst was dried at $423 \mathrm{~K}$ for $10 \mathrm{~h}$ before catalytic testing. The resulting material was referred to as HPWs@Meso-HKUST-1.

\subsection{Characterization}

Powder X-ray diffraction (XRD) patterns were recorded on a Rigaku D/max-rB spectrometer with $\mathrm{Cu} K_{\alpha}$ radiation, which was operated at $60 \mathrm{~mA}$ and $40 \mathrm{kV}$. The FT-IR measurements were performed using an IR Prestige-21 spectrometer (SHIMADZU) using the KBr pellet technique. Nitrogen adsorption and desorption isotherms were measured at $77 \mathrm{~K}$ using a Micromeritics ASAP 2020 instrument after the samples were degassed $\left(1.33 \times 10^{-2} \mathrm{~Pa}\right)$ at $423 \mathrm{~K}$ overnight. The Langmuir surface area was estimated from the adsorption branch according to the Langmuir equation [36]. The BET surface area was calculated using adsorption data within the relative pressure range 0.05 to 0.25 . The mesopore pore volume was obtained from the BJH cumulative specific adsorption volume according to the literature [31]. The mesopore size distributions were calculated from the BJH model. Micrographs obtained from transmission electron microscopy (TEM) were from a Philips Tecnai F20 transmission electron microscope. The samples were supported on carbon-coated copper grids prior to observation. The HPW contents were determined by means of inductively coupled plasma optical emission spectroscopy (Thermo ICP-OES 6500). UV-Vis DR spectra were collected on a Shimadzu UV-2540 spectrometer using $\mathrm{BaSO}_{4}$ as a reference. The in situ FT-IR spectra using $\mathrm{CO}$ as a probe molecule were collected on a BRUKER (Tensor 27) spectrophotometer equipped with a DTGS detector at $4 \mathrm{~cm}^{-1}$ resolution on a thin self-supported wafer. The sample was activated in a home-made cell under high vacuum (residual pressure $1 \times 10^{-2}$ $\mathrm{Pa})$ at $473 \mathrm{~K}$ for $2 \mathrm{~h}$. CO gas ( $p=6.7 \mathrm{kPa}$ ) was dosed on the sample for $20 \mathrm{~min}$ at RT.

\subsection{Activity test}

The activity test was performed at $303 \mathrm{~K}$ for $36 \mathrm{~h}$ with magnetic stirring in a closed $100-\mathrm{mL}$ regular glass reactor using $t$-butylhydroperoxide (TBHP) as the oxygen-donor and acetonitrile (MeCN) as the solvent. Quantitative analysis of the reaction products was performed by GC and the identification of different products in the reaction mixture was determined by means of GC-MS. Details can be found elsewhere [37,38].

\section{Results and discussion}

\subsection{Catalyst characterization}

Figure 1 (a) shows the $\mathrm{N}_{2}$ adsorption-desorption isotherms. Table 1 shows the textural properties of the obtained Meso-HKUST-1 and HPWs@Meso-HKUST-1 samples acquired from low-temperature $\mathrm{N}_{2}$ adsorption measurements. Fig. 1(b) shows the pore size distributions for each sample. In relation to the pure Meso-HKUST-1 sample, the very unique style of the $\mathrm{N}_{2}$ adsorption-desorption isotherm is attributed to the combination of type I, which is characteristic of microporous materials at low relative pressure, and type IV, which is characteristic of mesoporous materials with type $\mathrm{H} 2$ hysteresis at higher relative pressure. These results, in combination with the pronounced hysteresis in the $\mathrm{N}_{2}$ isotherm, provide evidence for a porous structure constructed from both mesopores and micropores $[31,39,40]$. The BET surface area is given to be 611 $\mathrm{m}^{2} / \mathrm{g}$ with a mesopore volume of $0.25 \mathrm{~cm}^{3} / \mathrm{g}$. In addition to the mesopores with a diameter of $3.9 \mathrm{~nm}$ (Fig. 1(b)), the sample contained micropores with a diameter of $0.82 \mathrm{~nm}$, which is in agreement with the micropore diameter $(0.85 \mathrm{~nm})$ estimated from the crystallographic data for microporous HKUST-1 [15]. These results are in agreement with those reported by Qiu et al. [31] and further demonstrate that, by using a supramolecular
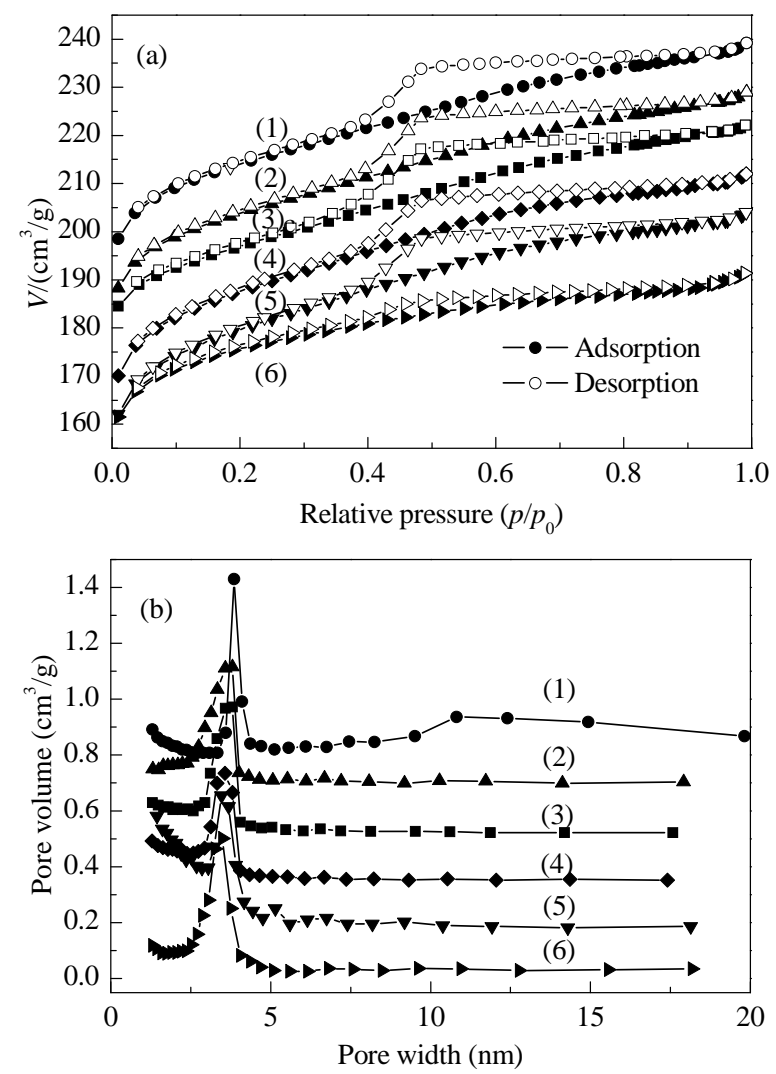

Fig. 1. (a) Nitrogen adsorption-desorption isotherms and (b) pore size distributions for (1) Meso-HKUST-1; (2) 8 wt\%; (3) 18 wt\%; (4) 25 wt\%; (5) 30 wt\%; (6) 33 wt\% HPWs@Meso-HKUST-1. 
Table 1

Physicochemical parameters of Meso-HKUST-1 as a function of HPW loading.

\begin{tabular}{|c|c|c|c|c|}
\hline Sample & $\begin{array}{c}S_{\text {Langmuir }} \\
\left(\mathrm{m}^{2} / \mathrm{g}\right)\end{array}$ & $\begin{array}{c}S_{\text {BET }} \\
\left(\mathrm{m}^{2} / \mathrm{g}\right)\end{array}$ & $\begin{array}{c}\text { Mesopore } \\
\text { diameter } \\
(\mathrm{nm})\end{array}$ & $\begin{array}{c}\text { Mesopore } \\
\text { volume } \\
\left(\mathrm{cm}^{3} / \mathrm{g}\right) \\
\end{array}$ \\
\hline Meso-HKUST-1 & 863 & 611 & 3.9 & 0.25 \\
\hline 8 wt\% HPWs@Meso-HKUST-1 & 557 & 426 & 3.8 & 0.23 \\
\hline 18 wt\% HPWs@Meso-HKUST-1 & 559 & 401 & 3.8 & 0.21 \\
\hline 25 wt\% HPWs@Meso-HKUST-1 & 480 & 379 & 3.6 & 0.20 \\
\hline 30wt\%HPWs@Meso-HKUST-1 & 452 & 347 & 3.6 & 0.19 \\
\hline 33 wt\% HPWs@Meso-HKUST-1 & 432 & 315 & 3.5 & 0.15 \\
\hline
\end{tabular}

template such as CTAB, mesoporous HKUST-1 with a hierarchical structure was successfully fabricated, in which the mesopore walls consisted of microporous frameworks [39]. After the introduction of HPW to the synthetic system, the $\mathrm{N}_{2}$ adsorption desorption isotherms for the HPWs@Meso-HKUST-1 samples maintained the same shape as that for the Meso-HKUST-1 sample; however, a reduction in the uptake capacity was observed. These results clearly demonstrate that hierarchically micro- and mesoporous HKUST-1-encapsulated HPW samples can be obtained by a supramolecular template strategy via a one-pot synthesis method. As shown in Fig. 1(a), a noticeable shrinkage of the hysteresis loop was observed as a function of increasing HPW content, which in turn affected the meso-textural properties of the HPWs@Meso-HKUST-1 samples. The BET surface area, mesopore diameter, and volume of these samples significantly decreased because of the incorporation of HPWs into the mesoporous cages of the Meso-HKUST-1 support (Fig. 1 and Table 1).

Notably, Wee et al. [41] fabricated a hierarchical variant of microporous cubic HKUST-1 by a dual-templating approach at room temperature involving HPW and CTAB as the structure-directing agents, which has strictly repetitive mesopores having a width of $5 \mathrm{~nm}$ separated by uniform microporous walls. The MOF framework of this new material, termed COK-15, is stabilized by HPW being systematically occluded in the cavities constituting the walls between the mesopores. The group postulated that HPW, when added to the hydrothermal synthesis, was observed in the cavities of MOFs; however, at room temperature, a strong interaction was observed between $\mathrm{Cu}(\mathrm{II})$ and the Keggin-type HPW. Thus, in the presence of CTAB and under mild conditions, the Keggin ions served as a molecular template for the structural motif of the MOF, while CTAB directed these units in an ordered mesoporous structure. According to the above discussion, it is clear that the HPW molecules of HPWs@Meso-HKUST-1 samples, synthesized via a one-pot hydrothermal synthesis herein, are encapsulated in the mesopore cages of the Meso-HKUST-1 MOF.

XRD patterns of the synthesized materials shown in Fig. 2 are compared with that of HPW, in addition to a simulated diffractogram using the crystallographic data of HKUST-1 [15]. The pattern of the as-made Meso-HKUST-1 was in perfect agreement with the simulated pattern of microporous HKUST-1, confirming the phase purity of the synthesized Meso-HKUST-1. The results demonstrate that the crystal structure of HKUST-1 is well maintained using CTAB as the struc-

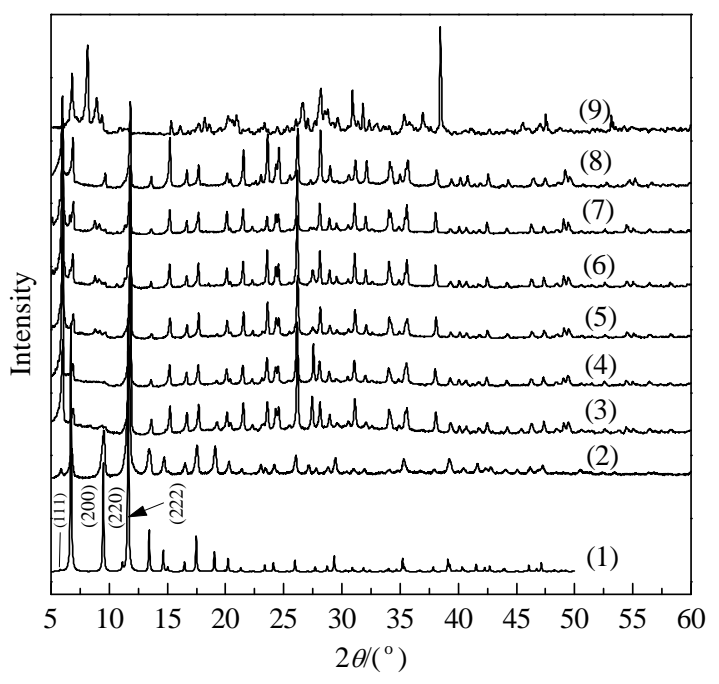

Fig. 2. XRD patterns of various samples. (1) HKUST-1, simulated from X-ray data of HKUST-1 single crystal [15]; (2) Meso-HKUST-1; (3) 8 wt\%; (4) 18 wt\%; (5) 25 wt\%; (6) 30 wt\%; (7) 33 wt\% HPWs@Meso-HKUST-1; (8) 30 wt\% after the third reaction cycle; (9) HPW.

ture-directing agent for preparing the mesostructured HKUST-1 MOF. Weak and broad diffraction peaks indicate that Meso-HKUST-1 is composed of small nanoscale crystals, which are approximately $24 \mathrm{~nm}$, as calculated by the application of the Scherrer formula on the (222) diffraction peak. Furthermore, the small-angle XRD (SXRD) pattern of Meso-HKUST-1 exhibited a single low-angle diffraction peak at $2 \theta=1.38^{\circ}$ (not shown), suggesting a disordered mesostructure without long-range order in the arrangement of the mesopores [31,42]. Meanwhile, regarding the HPWs@Meso-HKUST-1 samples, there was no observable difference in the small-angle XRD patterns when compared with the bare sample of Meso-HKUST-1, indicating that the HPWs@Meso-HKUST-1 samples also exhibit a disordered mesostructure without long-range order. Additionally, the wide-angle XRD patterns of the HPWs@Meso-HKUST-1 samples were in good agreement with those of Meso-HKUST-1 and the reported microporous HKUST-1, demonstrating that the crystal structure appears to be unchanged after the encapsulation of HPWs into Meso-HKUST-1. Nonetheless, some deviation was observed with respect to the relative intensity at $2 \theta$ between $5.0^{\circ}$ and $10.0^{\circ}$. By comparing the intensity ratio of $I_{(111)} / I_{(200)}$ for the pristine Meso-HKUST-1 sample with that of the HPWs@Meso-HKUST-1 samples, the ratio significantly increased and then gradually decreased as a function of increasing HPW. Another noticeable deviation is the intensity of the $I_{(220)}$ reflection $\left(\sim 9^{\circ}\right)$. However, in this case an opposite trend to the $I_{(111)} / I_{(200)}$ ratio is observed - that is, the $I_{(220)}$ intensity decreases and then increases as a function in increasing HPW content. Such differences in the diffractograms are thought to result from the introduction of HPW into the cavities of the Meso-HKUST-1 material, which is consistent with the results reported by Férey et al. [43]. HPW peak reflections in the XRD patterns are weakly detected at $2 \theta$ between $5.0^{\circ}$ and $10.0^{\circ}$ and between $21.0^{\circ}$ and $25.0^{\circ}$, and the other peaks of HPW cannot be obtained from the XRD patterns 
of Meso-HKUST-1-encapsulated HPWs, which implies the even distribution of HPWs and the absence of large HPW crystals on the outer surface of Meso-HKUST-1. Fig. 2 also shows the XRD pattern of the $30 \mathrm{wt} \%$ HPWs@Meso-HKUST-1 sample after the third reaction cycle; the pattern was almost identical to that of the freshly prepared catalyst, demonstrating that the Meso-HKUST-1 crystal structure is highly stable for the selective oxidation of CPE using TBHP and MeCN as the oxidant and solvent, respectively.

TEM is an important technique for mesostructured characterization. Fig. 3 shows several representative TEM micrographs of Meso-HKUST-1, freshly prepared $30 \mathrm{wt} \%$ HPWs@Meso-HKUST-1, and the catalyst after three catalytic cycles. It is difficult to obtain high-quality TEM micrographs because the HPWs@Meso-HKUST-1 samples have small mesopore diameters and pore volumes, in addition to the beam-sensitive properties of MOFs. The TEM micrographs of the synthesized Meso-HKUST-1, $30 \quad$ wt $\%$ HPWs@Meso-HKUST-1, and the catalyst after three cycles exhibited disordered worm-hole mesopore structure, which corroborates well with the results obtained from SXRD and $\mathrm{N}_{2}$ adsorption measurements, confirming the mesoporosity of the samples. Furthermore, the bright areas in the TEM micrographs indicate the positions of the mesopore openings. As the mesopores had worm-like channels and were not parallel to other channels, the orientation of the channels varied, resulting in the various sizes observed for the mesopore openings. On comparing the TEM micrographs of the three samples shown in Fig. 3, no significant change was observed in the morphology for the Meso-HKUST-1 and 30 wt\% HPWs@Meso-HKUST-1 materials, indicating that HPWs encapsulated in Meso-HKUST-1 do not alter the Meso-HKUST-1 structure. Regarding the catalyst after the three catalytic cycles, the degree of disorder in the worm-hole structure increased, which may have resulted from the liquid-phase reaction processes. However, their crystal structure remained unchanged according to the XRD results.

FT-IR measurements were performed to determine whether the Meso-HKUST-1 and HPW structure were preserved in the composite materials. Fig. 4 shows the FT-IR spectra of different materials in the skeletal mode region. The HPWs possessing Keggin structures exhibited several strong and typical FT-IR bands at 1084 (stretching frequency of $\mathrm{P}-\mathrm{O}$ in the central $\mathrm{PO}_{4}$

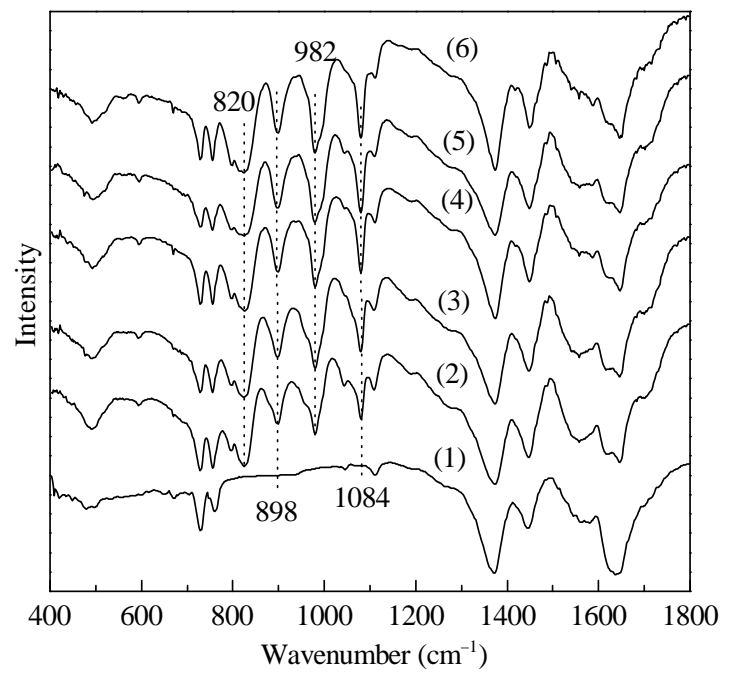

Fig. 4. FT-IR spectra of various samples. (1) Meso-HKUST-1; (2) 18 wt\%; (3) 25 wt\%; (4) 30 wt\%; (5) 33 wt\% HPWs@Meso-HKUST-1; (6) 30 wt\% HPWs@Meso-HKUST-1 after the third reaction cycle.

tetrahedron), 985 (terminal bands for $\mathrm{W}=\mathrm{O}$ in the exterior $\mathrm{WO}_{6}$ octahedron), 889 and $808 \mathrm{~cm}^{-1}$ (bands for the $\mathrm{W}-\mathrm{O}_{\mathrm{b}}-\mathrm{W}$ and $\mathrm{W}-\mathrm{O}_{\mathrm{c}}-\mathrm{W}$ bridges, respectively) $[44,45]$. The spectra of the HPWs@Meso-HKUST-1 samples contained not only typical IR bands corresponding to Meso-HKUST-1 but also typical IR bands belonging to HPW with Keggin structure, revealing that the HPW structure remains intact even when encapsulated in the mesopores of Meso-HKUST-1. However, the characteristic bands at 889 and $808 \mathrm{~cm}^{-1}$ shifted to higher wavenumbers, probably because of confinement effects of the pores within the Meso-HKUST-1 matrix for the guest HPW molecules. The same phenomenon was also observed for MIL-101 reported by Zhang et al. [46]. For the 30 wt\% HPWs@Meso-HKUST-1 sample, the FT-IR spectra were the same after the third catalytic cycle, indicating that the HPWs@Meso-HKUST-1 material has a highly stable structure in the selective oxidation reaction system, which is in agreement with the XRD result.

CO adsorption followed by in situ infrared spectroscopy was employed to investigate the nature of the acid sites residing on the surface of Meso-HKUST-1 and HPWs-encapsulated Meso-HKUST-1 materials (30 wt\% HPWs@Meso-HKUST-1). Fig. 5 shows the FT-IR spectra of the samples recorded after outgas-
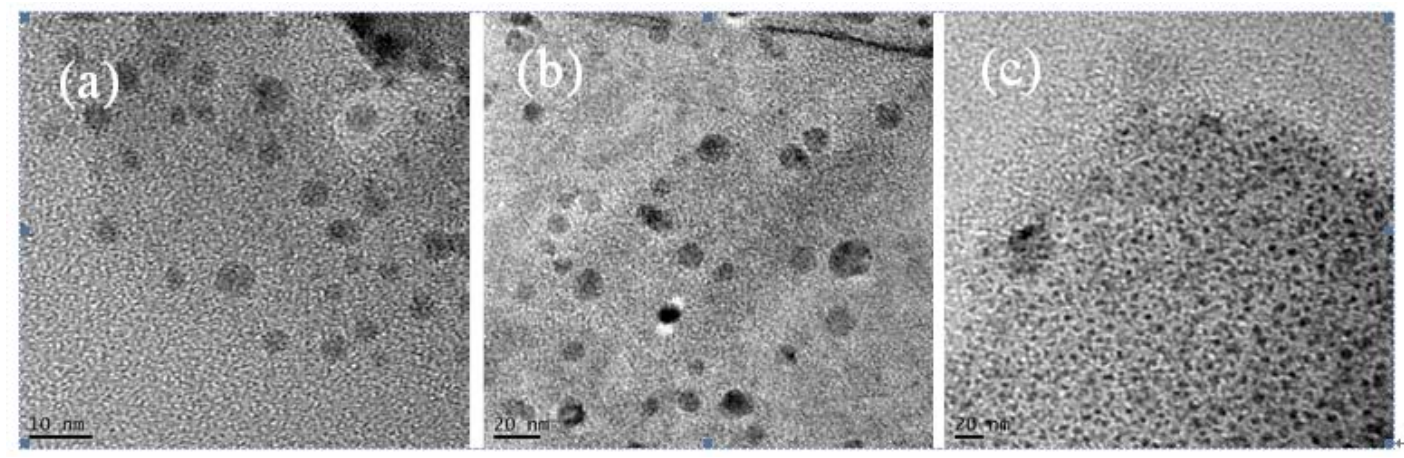

Fig. 3. TEM micrographs of various samples. (a) Meso-HKUST-1; (b) 30 wt\% HPWs@Meso-HKUST-1; (c) 30 wt\% HPWs@Meso-HKUST-1 after the third reaction cycle. 


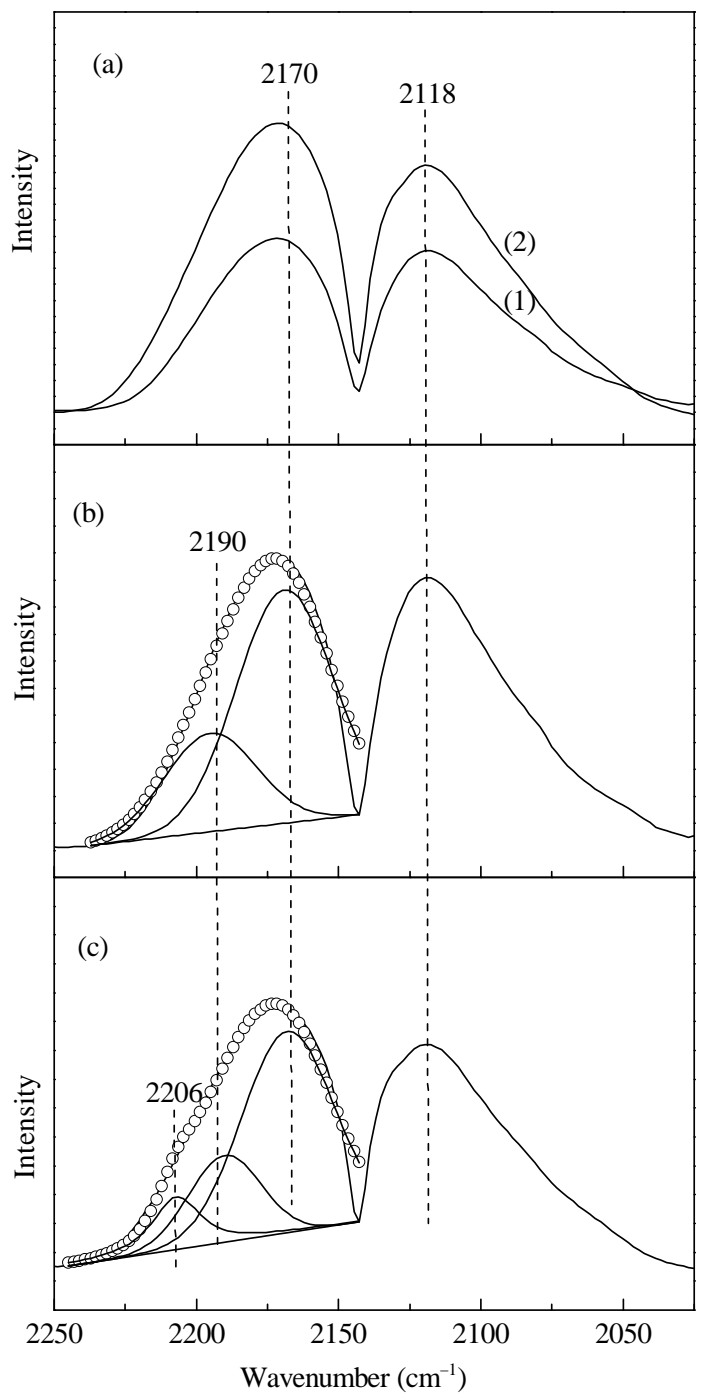

Fig. 5. (a) FT-IR spectra of (1) Meso-HKUST-1 and (2) 30 wt\% HPWs@Meso-HKUST-1 recorded after outgassing at $473 \mathrm{~K}$ for $2 \mathrm{~h}$, after adsorption of $\mathrm{CO}$ at room temperature; (b) and (c) peak-fitting FT-IR spectra of Meso-HKUST-1 and 30 wt\%HPWs@Meso-HKUST-1, respectively.

sing at $473 \mathrm{~K}$ for $2 \mathrm{~h}$, after adsorption of $\mathrm{CO}$ at room temperature. Both samples display two intense and broad bands positioned at 2118 and $2170 \mathrm{~cm}^{-1}$ (Fig. 5(a)). The former corresponds to CO physisorbed species $[47,48]$. The latter band has been reported to relate to the heterogeneity of the Lewis acid sites in Meso-HKUST-1 [48]. After HPWs were incorporated into Meso-HKUST-1, the band at $2170 \mathrm{~cm}^{-1}$ increased in intensity and became broader. To establish the difference between the two samples, a curve-fitting procedure was adopted to analyze the broad band centered at $2170 \mathrm{~cm}^{-1}$ according to previous works investigating Lewis sites in MIL-100 materials reported by Daturi's group [48]. Peak-fitting results of the FT-IR spectra corresponding to the two samples are summarized in Fig. 5(b) and 5(c). For the Meso-HKUST-1 sample, two main $v(\mathrm{CO})$ bands are obtained $\left(2170\right.$ and $2190 \mathrm{~cm}^{-1}$, Fig. 5(b)), which are assigned to CO coordinated on Lewis acid sites; that is, coordinative $\mathrm{Cu}$ sites. However, for the $30 \mathrm{wt} \%$
HPWs@Meso-HKUST-1 sample, in addition to the two 2170 and $2190 \mathrm{~cm}^{-1}$ bands in common with the Meso-HKUST-1 sample, a third band centered at $2206 \mathrm{~cm}^{-1}$ was observed (Fig. 5(c)). The assignment is not straightforward; however, one hypothesis is the presence of secondary Lewis acid sites, differing from the $\mathrm{Cu}^{2+}$ environment present in the Meso-HKUST-1 sample. The newly formed Lewis acid sites are possibly formed by two new species: (i) a series of defects form during the encapsulation of the polyanion forming new Lewis acid sites, or (ii) $\mathrm{Cu}^{2+}$ sites possessing varying acidity because of the presence of HPWs [47]. This is in agreement with observations on Cr-MIL-101 encapsulated HPWs, an active nanomaterial for catalyzing the alcoholysis of styrene oxide [47]. The CO probing study reveals that an additional Lewis acid site is noted for the 30 wt\% HPWs@Meso-HKUST-1 sample, which is essential to catalyze the selective oxidation of CPE to GA.

Figure 6 shows a comparison of the UV-Vis diffuse reflectance spectra of the different HPW-encapsulated samples with those of the bare Meso-HKUST-1 and bulk HPWs. Two main absorptions were observed in the HPW spectrum: the first was centered at $255 \mathrm{~nm}$, which is attributed to the oxygen-tungsten charge-transfer absorption band for Keggin anions; the second broad absorption in HPW was centered at $360 \mathrm{~nm}[49,50]$. Furthermore, two broad absorptions were also observed at 300 and $600 \mathrm{~nm}$, respectively, in the spectra of the bare Meso-HKUST-1 sample, which may be attributed to the oxygen-copper charge-transfer absorption bands in Meso-HKUST-1. On the addition of HPW, in addition to the bands of the Meso-HKUST-1 support, HPWs@Meso-HKUST-1 samples displayed the bands of HPW at 255 and $360 \mathrm{~nm}$. These results provide clear evidence of the presence of HPW, further indicating that the Keggin molecules are intact after direct inclusion in the porous structure.

\subsection{Catalytic activity tests for the selective oxidation of CPE to GA}

The catalytic performance of the new HPWs@Meso-

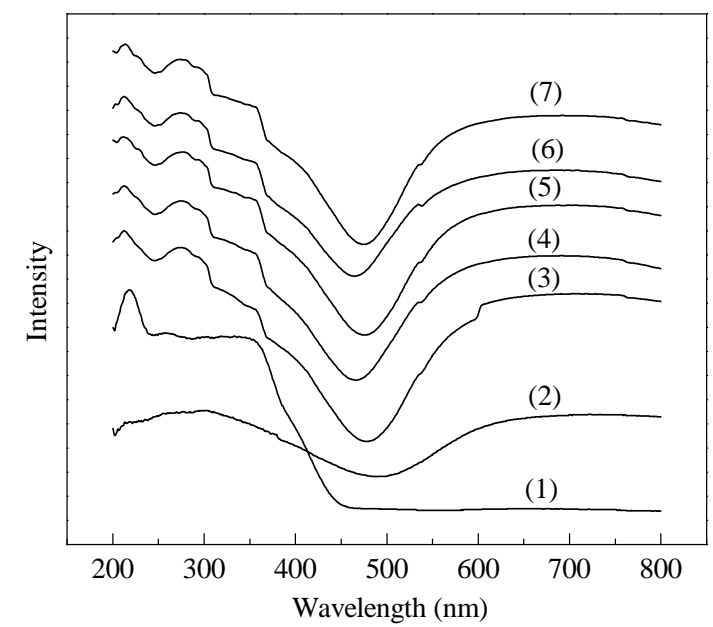

Fig. 6. UV-Vis diffuse reflectance spectra of various samples. (1) HPW; (2) Meso-HKUST-1; (3) 8 wt\%; (4) 18 wt\%; (5) 25 wt\%; (6) 30 wt\% HPWs@Meso-HKUST-1; (7) 33 wt\% HPWs@Meso-HKUST-1. 
HKUST-1 materials was assessed for the selective oxidation of CPE to GA with TBHP in MeCN. Aqueous $\mathrm{H}_{2} \mathrm{O}_{2}$ and tert-butyl alcohol were also chosen as the oxidant and solvent, respectively. However, $\mathrm{H}_{2} \mathrm{O}_{2}$ rapidly decomposed and released a significant amount of bubbles upon adding the HPWs@Meso-HKUST-1 catalyst to the reaction system, which may be caused by the Meso-HKUST-1 material.

Table 2 shows the results of the selective oxidation of CPE to GA over several HPWs@Meso-HKUST-1 catalysts, along with experiments performed in the presence of pristine Meso-HKUST-1 and the corresponding homogeneous HPW. For the purpose of comparison, the catalysts used in these experiments contained the equivalent amounts of HPWs. As shown in Table 2, the HPW catalyst exhibited excellent activity for oxidation. However, further recycling of the homogeneous catalytic system was restricted as a result of separation difficulties and reuse of the homogeneous catalyst. The pristine Meso-HKUST-1 exhibited marginal activity for the selective oxidation of CPE to GA, whereas the samples with HPWs well dispersed on the Meso-HKUST-1 support exhibited substantial activity and selectivity for the cleavage reaction. This result indicates that the HPWs incorporated in the 3D framework of the Meso-HKUST-1 material serve as active centers for the selective oxidation of CPE. The in situ FT-IR spectra demonstrated that HPWs encapsulated in the Meso-HKUST-1 materials can provide additional Lewis acid sites, which are different from those of the Meso-HKUST-1 supports and essential to catalyze the selective oxidation of CPE to GA. Although Meso-HKUST-1 shows a degree of catalytic performance for the reaction under study herein, the CPE conversion is very low and the Lewis acid sites are more suitable to generate cyclopentenone. For the HPWs@Meso-HKUST-1 catalysts, HPWs are the active centers and Meso-HKUST-1 materials are the supports, which provide high surface area and mesoporous cages to encapsulate HPWs. Thus, the catalyst can provide a large concentration of accessible, highly dispersed, and structurally well-confined active sites for the selective oxidation of CPE. Furthermore, CPE conversion is strongly dependent on the content of HPWs in the HPWs@Meso-HKUST-1 catalysts; this result reveals that the optimum catalyst possesses $30 \mathrm{wt} \%$ HPW. CPE conversion reached $92.5 \%$, and the GA yield reached $73.0 \%$ using the op-

Table 2

Catalytic performance in the selective oxidation of CPE over various samples.

\begin{tabular}{lrrrr}
\hline \multirow{2}{*}{ Sample } & CPE conver- & GA yield & \multicolumn{2}{c}{ Selectivity (\%) } \\
\cline { 5 - 6 } & sion (\%) & $(\%)$ & GA & CLPO \\
\hline Meso-HKUST-1 & 27.6 & 5.6 & 20.4 & 79.6 \\
HPWs & 100.0 & 56.3 & 56.3 & 43.7 \\
8 wt\% HPWs@Meso-HKUST-1 & 47.6 & 30.4 & 75.0 & 25.0 \\
18wt\% HPWs@Meso-HKUST-1 & 51.5 & 37.9 & 73.6 & 26.4 \\
25wt\% HPWs@Meso-HKUST-1 & 73.3 & 53.7 & 73.3 & 26.7 \\
30wt\% HPWs@Meso-HKUST-1 & 92.5 & 73.0 & 78.9 & 21.1 \\
33wt\% HPWs@Meso-HKUST-1 & 73.9 & 54.2 & 73.3 & 26.7 \\
30wt\% HPWs@HKUST-1 & 76.4 & 15.4 & 20.1 & 79.9 \\
\hline
\end{tabular}

Reaction conditions: The molar ratio of CPE:TBHP:HPWs $=1000: 2500$ : 3 , the volume ratio of $\mathrm{MeCN} / \mathrm{CPE}=10$, reaction time $36 \mathrm{~h}$, reaction temperature $303 \mathrm{~K}$; CLPO, cyclopentenone.

* Prepared by a one-pot synthesis method with microporosity only. timum catalyst. However, increasing the HPW content to greater than $30 \mathrm{wt} \%$ results in a noticeable CPE conversion decrease (73.9\%), and a significantly lower yield (54.2\%) of GA was obtained. The results are likely to be attributed to the fact that an excess of HPWs inevitably affects the meso-textural properties of the HPWs@Meso-HKUST-1 samples. As compared with those of pure Meso-HKUST-1, the BET surface area, mesopore diameter, and volume of the HPWs@Meso-HKUST-1 sample significantly decreased (Table 1), thus hindering the mass transfer of the reactants to the active centers. The intriguing difference in the catalytic performance of these HPWs@Meso-HKUST-1 samples prompted the further investigation of the influence of the mesostructure on the catalytic performance, and Table 2 lists the catalytic result undergoing the selective oxidation reaction over 30 wt\% HPWs@HKUST-1 material containing microporosity only. The 30 wt $\%$ HPWs@HKUST-1 catalyst exhibited moderate activity for the selective oxidation of CPE with TBHP; however, the CPE conversion only reached $76.4 \%$, with a GA selectivity of $20.1 \%$, thus leading to a low GA yield. The reduced catalytic efficiency may be related to the fact that the microporous structure of 30 wt\% HPWs@HKUST-1 is not suitable for the formation of the larger bulky GA molecule, but rather is beneficial for the formation of the comparatively smaller molecules of cyclopentenone. The significant differences in the catalytic performance among the HPWs@Meso-HKUST-1 catalysts indicate that the HPW content affects the textural properties of the Meso-HKUST-1 MOF in the HPWs@Meso-HKUST-1 catalysts, thus leading to varying degrees of catalytic performance, and the presence of the highly dispersed HPWs in the MOF matrices having a mesostructure is necessary for the selective oxidation of CPE to GA using TBHP as the oxidant.

To optimize the product yield and selectivity, $30 \mathrm{wt} \%$ HPWs@Meso-HKUST-1 was selected as the catalyst (Table 3) for investigating the effects of varying reaction parameters (i.e., reaction temperature, reaction solvent, reaction time, catalyst loading, and TBHP concentration) on the selective oxidation of CPE to GA using TBHP as the oxidant. Table 3 lists the results of these observations. In general, the nature of the solvent plays an important role in catalytic reactions performed in the liquid phase. As the 30 wt\% HPWs@Meso-HKUST-1 catalyst is completely insoluble in organic solvents such as ethanol, tert-butyl alcohol, acetone, and $\mathrm{MeCN}$, the oxidation reaction using 30 wt\% HPWs@Meso-HKUST-1 as the catalyst was performed at $303 \mathrm{~K}$ in the presence of these organic solvents. As shown in entries 1-4, the conversion (and yield) for the selective oxidation of CPE to GA was $47.3 \%$ (27.4\%), $61.2 \%$ (48.8\%), $75.6 \%$ (60.5\%), and $92.5 \%$ (73.0\%), respectively. The results indicate that aprotic solvents are beneficial to the reaction, and $\mathrm{MeCN}$ is the best solvent for the reaction using TBHP as the oxidant. Since MeCN is the optimal solvent for the reaction, the effect of reaction temperatures on the title reaction was investigated in the presence of MeCN. As shown in entries 4-7, CPE conversion first increased linearly and then slightly decreased in the temperature range from 298 to 313 K. However, GA selectivity observably changed, leading to an optimum GA yield at $303 \mathrm{~K}$. The lower GA yield at $313 \mathrm{~K}$ may be attributed to the higher 
Table 3

Catalytic performance in the selective oxidation of CPE over $30 \mathrm{wt} \%$ HPWs@Meso-HKUST-1.

\begin{tabular}{lcccccc}
\hline Entry & Solvent & $T / \mathrm{K}$ & $t / \mathrm{h}$ & TBHP/CPE & $\begin{array}{c}\text { CPE conversion } \\
(\%)\end{array}$ & $\begin{array}{c}\text { GA yield } \\
(\%)\end{array}$ \\
\hline 1 & $\mathrm{C}_{2} \mathrm{H}_{5} \mathrm{OH}$ & 303 & 36 & 2.5 & 47.3 & 27.4 \\
2 & $\left(\mathrm{CH}_{3}\right)_{3} \mathrm{COH}$ & 303 & 36 & 2.5 & 61.2 & 48.8 \\
3 & $\mathrm{CH}_{3} \mathrm{COCH}_{3}$ & 303 & 36 & 2.5 & 75.6 & 60.5 \\
4 & $\mathrm{CH}_{3} \mathrm{CN}$ & 303 & 36 & 2.5 & 92.5 & 73.0 \\
5 & $\mathrm{CH}_{3} \mathrm{CN}$ & 298 & 36 & 2.5 & 84.9 & 66.7 \\
6 & $\mathrm{CH}_{3} \mathrm{CN}$ & 308 & 36 & 2.5 & 99.0 & 55.9 \\
7 & $\mathrm{CH}_{3} \mathrm{CN}$ & 313 & 36 & 2.5 & 98.9 & 55.4 \\
8 & $\mathrm{CH}_{3} \mathrm{CN}$ & 303 & 12 & 2.5 & 42.6 & 38.8 \\
9 & $\mathrm{CH}_{3} \mathrm{CN}$ & 303 & 24 & 2.5 & 52.8 & 46.9 \\
10 & $\mathrm{CH}_{3} \mathrm{CN}$ & 303 & 48 & 2.5 & 92.3 & 71.6 \\
11 & $\mathrm{CH}_{3} \mathrm{CN}$ & 303 & 36 & 1.5 & 54.9 & 49.7 \\
12 & $\mathrm{CH}_{3} \mathrm{CN}$ & 303 & 36 & 2.0 & 68.6 & 60.9 \\
13 & $\mathrm{CH}_{3} \mathrm{CN}$ & 303 & 36 & 3.0 & 87.3 & 52.4 \\
$14{ }^{\text {a }}$ & $\mathrm{CH}_{3} \mathrm{CN}$ & 303 & 36 & 2.5 & 74.3 & 58.0 \\
$15^{\text {b }}$ & $\mathrm{CH}_{3} \mathrm{CN}$ & 303 & 36 & 2.5 & 90.3 & 67.0 \\
$16^{\mathrm{c}}$ & $\mathrm{CH}_{3} \mathrm{CN}$ & 303 & 36 & 2.5 & 84.1 & 60.1 \\
\hline
\end{tabular}

Reaction conditions: The molar ratio of CPE:HPWs $=1000: 3$, the vol-

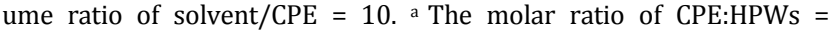
1000:2.5, the volume ratio of MeCN/CPE $=10$; ${ }^{\mathrm{b}}$ The molar ratio of CPE:HPWs $=1000: 3.5$, the volume ratio of $\mathrm{MeCN} / \mathrm{CPE}=10$; ${ }^{\mathrm{c}}$ The molar ratio of CPE:HPWs $=1000: 4$, the volume ratio of $\mathrm{MeCN} / \mathrm{CPE}=10$.

temperature, which results in further oxidation of GA to form over-oxidized by-products. On extending the reaction time from 6 to $36 \mathrm{~h}$ (entries 4 and 8-10), both CPE conversion and GA yield linearly increased and reached saturation after $36 \mathrm{~h}$ of reaction. Furthermore, on further increasing the reaction time, the CPE conversion and GA yield slightly decreased. Hence, the optimum reaction time is $36 \mathrm{~h}$. The effect of the TBHP amount on the selective oxidation of CPE to GA is shown in entries 4 and 11-13. By varying the molar ratio of TBHP to CPE from 1.5:1 to 2.5:1, both CPE conversion and GA yield increased, and TBHP was not detected in the reaction mixture (entries $4,11,12$ ). However, the conversion of CPE to GA decreased when the ratio of TBHP to CPE was increased to 3:1 (entry 13), thus suggesting that the optimum ratio of TBHP to CPE for the conversion of CPE to GA is 2.5:1. The effect of catalyst loading on the selective oxidation of CPE is shown in entries 4 and 14-16. Additionally, with increasing catalyst loading, the GA yield increased and reached a maximum of $73.0 \%$ when the molar ratio of HPWs to CPE reached $0.3 \%$. However, the CPE conversion and GA yield significantly decreased when the catalyst loading was increased to $0.4 \%$, which may be ascribed to the increased diffusion limitations of mass transfer during the reaction. This result suggests that the optimum molar ratio of HPW to CPE for the selective oxidation of CPE to GA is $0.3 \%$. According to the above results, it can be concluded that the 30 wt\% HPWs@Meso-HKUST-1 catalyst exhibits the best catalytic performance for the selective oxidation of CPE to GA using TBHP and MeCN as the oxidant and solvent, respectively, with a reaction temperature of $303 \mathrm{~K}$, a reaction time of $36 \mathrm{~h}$, and a molar ratio of HPW:TBHP:CPE of 3:2500:1000.

While studying liquid-phase processes over solid catalysts, it is extremely important to address the issue of the stability of the active component with respect to leaching and maintaining structural integrity of the catalyst under the reaction conditions. To investigate the stability and duration of the active HPW components in the 30 wt\% HPWs@Meso-HKUST-1 catalyst, a three-consecutive-cycle experiment was performed in the selective oxidation of CPE, and the HPWs remaining in the catalyst were determined by inductively coupled plasma analyses after the final cycle (Table 4). Approximately 3\%(w) HPWs leached from the catalyst after three consecutive cycles. However, such a loss of HPWs did not result in the appreciable decrease in CPE conversion. The CPE conversion decreased from $92.5 \%$ to $90.3 \%$, and the GA yield decreased from $73.0 \%$ to $70.1 \%$ under the same experimental conditions after three consecutive cycles. The XRD pattern and FT-IR spectrum of the 30 wt\% HPWs@Meso-HKUST-1 catalyst after three cycles of the selective oxidation of CPE revealed the principal peaks and bands of HPW and Meso-HKUST-1. Hence, we suppose that Meso-HKUST-1 and HPW supported on Meso-HKUST-1 maintain structural integrity during the three reaction cycles. Hill's group [51] has reported that the deactivation of homogeneous HPW is mainly caused by the reaction product. The HPWs-MIL-101 catalyst was also reported to be poisoned by the leaching of small amounts of HPW species and oxidized products [52]. To explain the reasons for the decrease of the catalytic performance, the catalysts were washed with ethanol and DMF to remove the adsorbed organic substances after the three-consecutive-cycle reactions. Thereafter, the catalytic activity was tested and the results are listed in Table 4 (entry 4). The catalytic activity compared with the third reaction cycle slightly increased; however, the degree of activity was below that of the fresh activity. Therefore, we believe that the slight decrease in the observed catalytic activity was caused by the leaching of small quantities of HPW species together with the adsorption of oxidized products on the catalyst. Thus, the 30 wt\% HPWs@Meso-HKUST-1 catalyst exhibits high stability and catalytic activity for the selective oxidation of CPE to GA.

Additionally, the nature of the catalyst is a significant factor in liquid-phase processes. After the reaction was subjected to 12 h over the 30 wt\% HPWs@Meso-HKUST-1 catalyst, the catalyst was removed from the experiment while under test conditions to verify the heterogeneity of the HPWs@MesoHKUST-1 catalyst in the reaction. No detectable increase was observed in the GA yield and CPE conversion after the catalysts were removed, indicating that the selective oxidation process is truly heterogeneous and occurs on the catalyst surface rather

Table 4

Re-usability of 30 wt\% HPWs@Meso-HKUST-1.

\begin{tabular}{lccccc}
\hline Recycle & CPE conversion & \multicolumn{2}{c}{ Selectivity (\%) } & Yield & HPW loading \\
\cline { 3 - 4 } entry & $(\%)$ & GA & CLPO & (\%) & (wt\%) \\
\hline 1 & 92.5 & 78.9 & 21.1 & 73.0 & 30 \\
2 & 91.6 & 78.3 & 21.7 & 71.7 & 28 \\
3 & 90.3 & 77.6 & 22.4 & 70.1 & 27 \\
$4^{*}$ & 91.2 & 78.5 & 21.5 & 71.6 & - \\
\hline
\end{tabular}

Reaction conditions: The molar ratio of CPE:TBHP:HPWs $=1000: 2500$ : 3 , the volume ratio of $\mathrm{MeCN} / \mathrm{CPE}=10$, reaction time $36 \mathrm{~h}$, reaction temperature $303 \mathrm{~K}$; CLPO = cyclopentenone.

* The catalyst was washed with ethanol and DMF to remove the adsorbed organic substances. 
than in the solution. Even if trace quantities of the HPW species leached from the catalyst during selective oxidation, the observed catalytic activity was not attributed to these species alone.

From the results of the catalytic activity tests and catalyst characterization, it can be concluded that the hierarchically micro- and mesoporous HKUST-1-encapsulated HPW sample (HPWs@Meso-HKUST-1) can be prepared by employing a supramolecular template strategy via a one-pot synthesis method. It is conceivable that the design of the mesoporous structure of Meso-HKUST-1-possessing high porosity and high surface area, in conjunction with microporous frameworks-is more suitable to encapsulate and confine HPWs into the mesoporous cages, and prevent leaching of active HPWs. Furthermore, the incorporation of HPWs into the mesoporous cages of hierarchical Meso-HKUST-1 enhances molecular diffusion and mass transfer, and further provides the catalysts with tailored properties, such as a large concentration of accessible, highly dispersed, additional Lewis acid sites, and structurally well-confined active sites for the selective cleavage of CPE. Hence, the HPWs@Meso-HKUST-1 catalysts exhibit high catalytic performance for the selective oxidation of CPE to GA.

\section{Conclusions}

In summary, a novel mesoporous MOF HKUST-1 with a hierarchical-structure-encapsulated HPW material (HPWs@ Meso-HKUST-1) was successfully prepared for the first time by a simple one-pot hydrothermal synthesis method using CTAB as the supramolecular template. The resulting material exhibited high activity and excellent re-usability in the selective oxidation of CPE to GA, behaving as a truly heterogenous oxidative catalyst without significant leaching of HPWs during reuse; the product maintains structural integrity of HKUST-1 with hierarchical micro- and mesopores. The unique textural properties of Meso-HKUST-1 and the well-dispersed HPWs confined in the mesoporous cages of the Meso-HKUST-1 matrix together with an appropriate HPW loading providing additional Lewis acid sites may account for the high catalytic properties of HPWs@ Meso-HKUST-1. The developed HPWs@ Meso-HKUST-1 has the potential to be used as an industrial catalyst.

\section{References}

[1] Kozhevnikov I V. Chem Rev, 1998, 98: 171

[2] Inumaru K, Ishihara T, Kamiya Y, Okuhara T, Yamanaka S. Angew Chem Int Ed, 2007, 46: 7625

[3] Bigi F, Corradini A, Quarantelli C, Sartori G.J Catal, 2007, 250: 222

[4] Khder A E R S. Appl Catal A, 2008, 343: 109

[5] Schwegler M A, Vinke P, van der Eijk M, van Bekkum H. Appl Catal A, 1992, 80: 41

[6] Dupont P, Védrine J C, Paumard E, Hecquet G, Lefebvre F. Appl Catal A, 1995, 129: 217

[7] Nomiya K, Murasaki H, Miwa M. Polyhedron, 1986, 5: 1031

[8] Kozhevnikov I V, Kloetstra K R, Sinnema A, Zandbergen H W, van Bekkum H. J Mol Catal A, 1996, 114: 287

[9] Yuan C Y, Chen J. Chin J Catal (袁程远, 陈静. 催化学报), 2011, 32: 1191

[10] Khder A E R S, Khder, Hassan H M A, El-Shall M S. Appl Catal A, 2012, 411-412: 77

[11] Ferey G. Chem Soc Rev, 2008, 37: 191

[12] Long J R, Yaghi O M. Chem Soc Rev, 2009, 38: 1213

[13] Dhakshinamoorthy A, Garcia H. Chem Soc Rev, 2012, 41: 5262

[14] Prestipino C, Regli L, Vitillo J G, Bonino F, Damin A, Lamberti C, Zecchina A, Solari P L, Kongshaug K 0, Bordiga S. Chem Mater, 2006, 18: 1337

[15] Chui S S Y, Lo S M F, Charmant J P H, Orpen A G, Williams I D. Science, 1999, 283: 1148

[16] Schlichte K, Kratzke T, Kaskel S. Microporous Mesoporous Mater, 2004, 73: 81

[17] Alaerts L, Séguin E, Poelman H, Thibault-Starzyk F, Jacobs P A, De Vos D E. Chem Eur J, 2006, 12: 7353

[18] Dhakshinamoorthy A, Alvaro M, Garcia H. J Catal, 2009, 267: 1

[19] Wu Y, Qiu L G, Wang W, Li Z Q, Xu T, Wu Z Y, Jiang X. Trans Met Chem, 2009, 34: 263

[20] Brown K, Zolezzi S, Aguirre P, Venegas-Yazigi D, Paredes-Garcia V, Baggio R, Novak M A, Spodine E. Dalton Trans, 2009: 1422

[21] Marx S, Kleist W, Baiker A. J Catal, 2011, 281: 76

[22] Sun C Y, Liu S X, Liang D D, Shao K Z, Ren Y H, Su Z M. J Am Chem

\section{Graphical Abstract}

Chin. J. Catal., 2015, 36: 1875-1885 doi: 10.1016/S1872-2067(15)60972-X

\section{One-pot synthesis of a hierarchical microporous-mesoporous phosphotungstic acid-HKUST-1 catalyst and its application in the selective oxidation of cyclopentene to glutaraldehyde}

Xinli Yang *, Liming Qiao, Weilin Dai *

Henan University of Technology; Fudan University

A hierarchical microporous-mesoporous MOF of HKUST-1(Cu)-encapsulated phosphotungstic acid (HPW) material, referred to as HPWs@Meso-HKUST-1, was prepared by a one-pot synthesis method using cetyltrimethylammonium bromide as the supramolecular template for the selective oxidation of cyclopentene to glutaraldehyde.

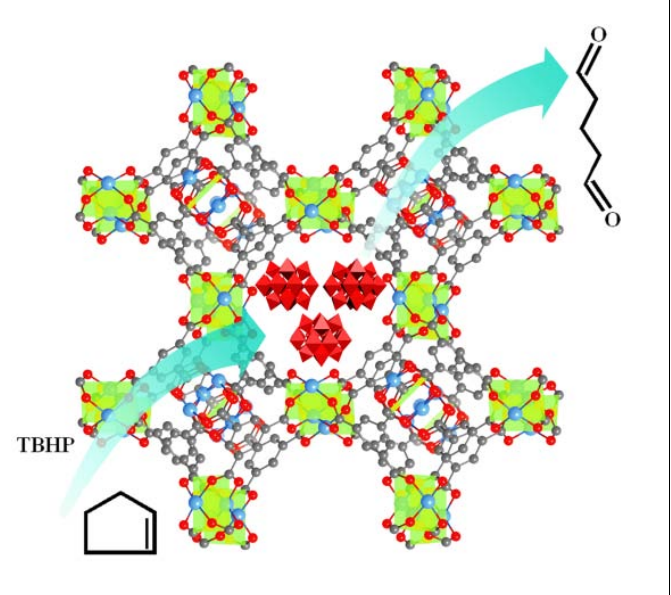


Soc, 2009, 131: 1883

[23] Janssens N, Wee L H, Bajpe S, Breynaert E, Kirschhock C E A, Martens J A. Chem Sci, 2012, 3: 1847

[24] Song J, Luo Z, Britt D K, Furukawa H, Yaghi O M, Hardcastle K I, Hill C L. J Am Chem Soc, 2011, 133: 16839

[25] Yang H, Li J, Wang L Y, Dai W, Lü Y, Gao S. Catal Commun, 2013, 35 : 101

[26] Wee L H, Janssens N, Bajpe S R, Kirschhock C E A, Martens J A. Catal Today, 2011, 171: 275

[27] Klein N, Senkovska I, Gedrich K, Stoeck U, Henschel A, Mueller U, Kaskel S. Angew Chem Int Ed, 2009, 48: 9954

[28] Fang Q R, Makal T A, Young M D, Zhou H C. Comments Inorg Chem, 2010, 31: 165

[29] Xuan W M, Zhu C F, Liu Y, Cui Y. Chem Soc Rev, 2012, 41: 1677

[30] Song L F, Zhang J, Sun L X, Xu F, Li F, Zhang H Z, Si X L, Jiao C L, Li Z B, Liu S, Liu Y L, Zhou H Y, Sun D L, Du Y, Cao Z, Gabelica Z. Energy Environ Sci, 2012, 5: 7508

[31] Qiu L G, Xu T, Li Z Q Wang W, Wu Y, Jiang X, Tian X Y, Zhang L D. Angew Chem Int Ed, 2008, 47: 9487

[32] Furukawa H, Nakamura T, Inagaki H, Nishikawa E, Imai C, Misono M. Chem Lett, 1988: 877

[33] Furukawa H, Nishikawa E, Koyama T. JP Patent 62029546. 1987

[34] Deng J F, Xu X H, Chen H Y, Jiang A R. Tetrahedron, 1992, 48: 3503

[35] Schlichte K, Kratzke T, Kaskel S. Microporous Mesoporous Mater, 2004, 73: 81

[36] Yuan D Q Lu W G, Zhao D, Zhou H C. Adv Mater, 2011, 23: 3723

[37] Chen H, Dai W L, Deng J F, Fan K N. Catal Lett, 2002, 81: 131

[38] Dai W L, Chen H, Cao Y, Li H X, Xie S H, Fan K N. Chem Commun,
2003: 892

[39] Gregg S J, Sing K S W. Adsorption, Surface Area and Porosity. London: Academic Press, 1997. 111

[40] Sun L B, Li J R, Park J, Zhou H C. J Am Chem Soc, 2012, 134: 126

[41] Wee L H, Wiktor C, Turner S, Vanderlinden W, Janssens N, Bajpe $S$ R, Houthoofd K, Van Tendeloo G, De Feyter S, Kirschhock C E A, Martens J A. J Am Chem Soc, 2012, 134: 10911

[42] Pauly T R, Liu Y, Pinnavaia T J, Billinge S J L, Rieker T P. J Am Chem Soc, 1999, 121: 8835

[43] Férey G, Mellot-Draznieks C, Serre C, Millange F, Dutour J, Surblé S, Margiolaki I. Science, 2005, 309: 2040

[44] Rao K M, Gobetto R, Iannibello A, Zecchina A. J Catal, 1989, 119: 512

[45] Damyanova S, Dimitrov L, Mariscal R, Fierro J L G, Petrov L, Sobrados I. Appl Catal A, 2003, 256: 183

[46] Zang Y D, Shi J, Zhao X M, Kong L C, Zhang F M, Zhong Y J. Reac Kinet Mech Catal, 2013, 109: 77

[47] Wee L H, Bonino F, Lamberti C, Bordiga S, Martens J A. Green Chem, 2014, 16: 1351

[48] Vimont A, Goupil J M, Lavalley J C, Daturi M, Surblé S, Serre C, Millange F, Férey G, Audebrand N. J Am Chem Soc, 2006, 128: 3218

[49] Youn M H, Kim H, Jung J C, Song I K, Barteau K P, Barteau M A. J Mol Catal A, 2005, 241: 227

[50] Juan-Alcañiz J, Ramos-Fernandez E V, Lafont U, Gascon J, Kapteijn F. J Catal, 2010, 269: 229

[51] Duncan D C, Chambers R C, Hecht E, Hill C L. J Am Chem Soc, 1995, 117: 681

[52] Hu X F, Lu Y K, Dai F N, Liu C G, Liu Y Q. Microporous Mesoporous Mater, 2013, 170: 36

\title{
一步法合成微-介孔多级孔道金属-有机骨架固载磷铇酸催化剂及其催化性能
}

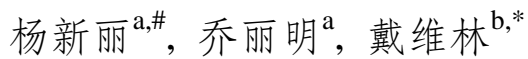 \\ a河南工业大学化学化工学院, 河南郑州 450001 \\ b复旦大学化学系, 上海200433
}

摘要: 磷铇酸具有酸性, 而且具有氧化还原性, 是一种多功能的新型催化剂, 具有很高的催化活性, 稳定性好, 既可作均相催化剂, 也可做多相催化剂. 磷钨酸作为多相催化剂主要负载于无机氧化物、介孔分子策、活性炭和离子交换树脂等材料中, 然而这些多 相催化剂存在着结构不明确, 磷铇酸分散不均、易流失、活性点易中毒等问题. 为了克服以上问题, 需要寻找更加合适的载体来 制备新颖的负载型的磷铇酸多相催化剂, 金属-有机骨架的独特性质, 使该材料成为一种优良的催化剂载体. 金属-有机骨架 (MOFs)又称配位聚合物, 是指由金属离子与有机配体通过配位键和其他一些弱作用力连接而成的具有超分子微孔网络结构的一 种颇具应用前途的类沸石材料. 这种材料具有丰富的孔结构和很大的比表面积, 同时具有孔结构规整、孔径大小设计可调、表面 化学基团修饰可调等优点, 使得它在吸附分离、多相催化、环境保护等领域具有很好的应用前景. HKUST-1 (Cu-BTC或MOF-199) 是该领域内研究和应用较多的一种金属-有机骨架材料, 它最早由香港大学Williams教授课题组报道, 其为面心立方晶体. 在结构 中, 每个 $\mathrm{Cu}_{2}$ 簇与四个均苯三甲酸相连, 每个均苯三甲酸桥连着三个 $\mathrm{Cu}_{2}$ 簇, 形成轮浆式次级结构单元. 这些次级结构单元相互交 错连接形成3D网络结构, 具有孔径约为 $0.9 \mathrm{~nm} \times 0.9 \mathrm{~nm}$ 的正方形孔道, 孔道中的客体分子可以除去, 并可以为其它的客体分子所 置换. HKUST-1本身即是一种优良的催化剂, 同时也可作为一种性能稳定的催化剂载体. 目前, 关于HKUST-1在催化领域中的应 用主要限制在微孔范围, 其较小的孔道不利于物质扩散和传输, 从而限制其实际应用.

本论文利用超分子模板法, 以十六烷基三甲基溴化铵(CTAB)为模板剂、铜为金属中心、均苯三甲酸为有机配体、磷铇酸 (HPWs) 为活性组分, 采用一步水热法合成微-介孔多级孔道金属-有机骨架固载磷铇酸催化剂HPWs@Meso-HKUST-1, 详细研究 了该催化剂对环戊烯选择氧化制备戌二醛的催化性能, 并采用X射线粉末衍射(XRD)、傅里叶红外光谱(FT-IR)、 $\mathrm{N}_{2}$ 吸附、透射电 镜(TEM)和室温CO原位吸附红外(CO-FT-IR)等表征手段对HPWs@Meso-HKUST-1催化剂进行了结构表征, 从而解释该催化剂对 目标反应具有优良催化性能的本质原因.

$\mathrm{N}_{2}$ 吸附表征结果说明, HPWs@Meso-HKUST-1催化剂的吸附-脱附曲线在低相对压力范围内呈现I型吸附等温线, 在高相对压 力范围内呈现具有 $\mathrm{H} 2$ 型滞后环的IV型吸附等温线; 催化剂独特的吸附等温线表明以CTAB为模板剂, 采用一步水热合成法可以 得到具有微孔和介孔多级孔道的催化剂材料. 催化剂的比表面积和孔容随着磷铇酸含量的增加而减少, 结合文献报道, 可以得出 
一步水热合成法使活性组分HPWs分布在载体的介孔孔道内. XRD和FT-IR测试结果表明, 一步水热合成法可以成功的将HPWs引 入HKUST-1中, 且HPWs高度分散在载体中; HPWs@Meso-HKUST-1催化剂保持了载体HKUST-1的骨架结构. 小角XRD和TEM 结果说明, 催化剂的多级孔结构为无序蠕虫状介孔组织. 室温CO-FT-IR 说明, 在HPWs@Meso-HKUST-1催化剂中, HPWs提供了 不同于载体HKUST-1的L酸酸性位. 从以上结果可以得出, 一步水热合成法使HPWs包裹在载体的介孔孔道内, 防止了HPWs的流 失, 使HPWs@Meso-HKUST-1催化剂为环戍烯选择氧化制备龙二醛提供了大量的、高度分散的、具有L酸酸性位的活性中心, 且 催化剂的介孔孔道有利于反应物和产物的扩散, 从而使该催化剂表现出优良的催化性能; 在优化条件下, 环戍烯的转化率达到 $92.5 \%$, 戊二醛的得率达到 $78.9 \%$; 热过滤实验表明该催化剂是真正的多相催化剂, 且至少可以重复使用3次.

关键词: 金属-有机骨架; HKUST-1; 磷铇酸; 环戊烯; 戊二醛

收稿日期: 2015-07-15. 接受日期: 2015-09-10. 出版日期: 2015-11-20.

*通讯联系人. 电话: (021)55664678; 传真: (021)55665701; 电子信箱: wldai@fudan.edu.cn

\#通讯联系人. 电话: (0371)67756193; 传真: (0371)67756718; 电子信箱: xlyang@haut.edu.cn

基金来源：河南工业大学自然科学基础研究重点培育计划(2013JCYJ09); 河南省省属高校基本科研业务费专项资金 (2014YWQQ13); 国家自然科学基金(20903035, 21373054).

本文的英文电子版由Elsevier出版社在ScienceDirect上出版(http://www.sciencedirect.com/science/journal/18722067). 